\title{
Do Código Florestal para o Código da Biodiversidade
}

\author{
Aziz Nacib Ab’Sáber ${ }^{1,2}$ \\ ${ }^{I}$ Departamento de Geografia, Instituto de Estudos Avançados, Faculdade de Filosofia, Letras e Ciências Humanas, \\ Universidade de São Paulo - USP, Av. Prof. Lineu Prestes, n. 338, Cidade Universitária, \\ CEP 05508-000, São Paulo, Brasil \\ ${ }^{2}$ Autor para correspondência: Aziz Nacib Ab’Sáber, e-mail: absaber@usp.br
}

AB'SÁBER, A.N. Evolving from a Forest Code to a Biodiversity Code. Biota Neotrop. 10(4): http://www. biotaneotropica.org.br/v10n4/en/abstract?point-of-view+bn01210042010.

\begin{abstract}
Given the enormity of the territory and the actual situation of the Brazilian macro biomes - Brazilian Amazonia, Brazilian Tropical Atlantic Forest, Cerrados of Central Brazil, Araucaria Plateau, and the Mixed Subtropical Grasslands of Brazil - and its numerous mini-biomes, transition areas and remnants of ecosystems, any attempt to change the Brazilian Forest Code has to be conducted by competent and bioethical sensitive persons. Any movement to improve the current Forest Code would have to broaden its scope and move towards a Biodiversity Code, to be able to consider properly the complexity of ecosystems and vegetation mosaics of our territory. While the whole world is working towards a radical reduction of $\mathrm{CO}_{2}$ emissions, the changes in the Forest Code approved by the Special Commission of the Brazilian Congress advocates a process that will result in a wave of deforestation and uncontrolled emissions of carbon dioxide, a fact already registered by many critics in several papers and interviews. The utopia of economic development with a maximum of standing forests can not be destroyed by radical changes in the Forest Code. It is necessary to think in the complexity of the whole territory, working with an expanded Biodiversity Code based in correct principles of development with environmental protection and biodiversity conservation. That means thinking about our great forests (Amazon and Atlantic Rain Forest), the domain of Caatingas and Agrestes; the Central Plateau covered by Cerrado, Cerradões and native grasslands; the highlands of Southern Brazil covered by Araucaria Forest; the mixed grasslands of the Pampas in Rio Grande do Sul; the refuge and mini-biomes from the Brazilian Cost and from the Pantanal, as well as al the transition zones between "core areas" of all morphoclimatic and phytogeographic Brazilian domains.

Keywords: Brazilian macro biomes, refuge and mini-biomes, complexity of ecosystems, vegetation mosaic.
\end{abstract}

AB'SÁBER, A.N. Do Código Florestal para o Código da Biodiversidade. Biota Neotrop. 10(4): http://www. biotaneotropica.org.br/v10n4/pt/abstract?point-of-view+bn01210042010.

Resumo: Em face do gigantismo do território e da situação real em que se encontram os seus macro biomas Amazônia Brasileira, Brasil Tropical Atlântico, Cerrados do Brasil Central, Planalto das Araucárias, e Pradarias Mistas do Brasil Subtropical - e de seus numerosos mini-biomas, faixas de transição e relictos de ecossistemas, qualquer tentativa de mudança no "Código Florestal" tem que ser conduzido por pessoas competentes e bioeticamente sensíveis. Por muitas razões, se houvesse um movimento para aprimorar o atual Código Florestal, teria que envolver o sentido mais amplo de um Código de Biodiversidades, levando em conta o complexo mosaico vegetacional de nosso território. Enquanto o mundo inteiro trabalha para a diminuição radical de emissão de $\mathrm{CO}_{2}$, o projeto de reforma proposto na Câmara Federal de revisão do Código Florestal defende um processo que significará uma onda de desmatamento e emissões incontroláveis de gás carbônico, fato observado por muitos críticos em diversos trabalhos e entrevistas. A utopia de um desenvolvimento com o máximo de florestas em pé não pode ser eliminada por princípio em função de mudanças radicais do Código Florestal, sendo necessário pensar no território total de nosso país, sob um ampliado e correto Código de Biodiversidade. Ou seja, um pensamento que envolva: as nossas grandes florestas (Amazônia e Matas Tropicais Atlânticas); o domínio das caatingas e agrestes sertanejos; planaltos centrais com cerrados, cerradões e campestres; os planaltos de araucárias sul-brasileiros; as pradarias mistas do Rio Grande do Sul; e os redutos e mini-biomas da costa brasileira e do Pantanal mato-grossense, e faixas de transição e contrato (core-áreas) de todos os domínios morfoclimáticos e fitogeográficos brasileiros).

Palavras-chave: macro biomas brasileiros, refúgios e mini-biomas, complexidade de ecossistemas, mosaico vegetacional. 


\section{Código da Biodiversidade}

Em face do gigantismo do território e da situação real em que se encontram os seus macro-biomas - Amazônia Brasileira, Brasil Tropical Atlântico, Cerrados do Brasil Central, Planalto das Araucárias, e Pradarias Mistas do Brasil Subtropical - e de seus numerosos mini-biomas, faixas de transição e relictos de ecossistemas, qualquer tentativa de mudança no "Código Florestal" tem que ser conduzido por pessoas competentes e bioeticamente sensíveis. Pressionar por uma liberação ampla dos processos de desmatamento significa desconhecer a progressividade de cenários bióticos, a diferentes espaços de tempo futuro. Favorecendo de modo simplório e ignorante os desejos patrimoniais de classes sociais que só pensam em seus interesses pessoais, no contexto de um país dotado de grandes desigualdades sociais. Cidadãos de classe social privilegiada, que nada entendem de previsão de impactos. Não tem qualquer ética com a natureza. Não buscam encontrar modelos tecnicocientificos adequados para a recuperação de áreas degradadas, seja na Amazônia, seja no Brasil Tropical Atlântico, ou alhures. Pessoas para as quais exigir a adoção de atividades agrárias "ecologicamente auto-sustentadas" é uma mania de cientistas irrealistas.

Por muitas razões, se houvesse um movimento para aprimorar o atual Código Florestal, teria que envolver o sentido mais amplo de um Código de Biodiversidades, levando em conta o complexo mosaico vegetacional de nosso território. Remetemos essa idéia para Brasília, e recebemos em resposta que essa era uma idéia boa, mas complexa e inoportuna (...). Entrementes, agora outras personalidades trabalham por mudanças estapafúrdias e arrasadoras no chamado Código Florestal. Razão pela qual ousamos criticar aqueles que insistem em argumentos genéricos e perigosos para o futuro do país. Sendo necessário, mais do que nunca, evitar que gente de outras terras, sobretudo de países hegemônicos, venha a dizer que fica comprovado que o Brasil não tem competência para dirigir a Amazônia (...). Ou seja, os revisores do atual Código Florestal não teriam competência para dirigir o seu todo territorial do Brasil. Que tristeza, gente minha!

\section{Os Erros da Revisão do Código Florestal}

O primeiro grande erro dos que no momento lideram a revisão do Código Florestal brasileiro - a favor de classes sociais privilegiadas diz respeito à chamada estadualização dos fatos ecológicos de seu território especifico. Sem lembrar que as delicadíssimas questões referentes à progressividade do desmatamento exigem ações conjuntas dos órgãos federais específicos, em conjunto com órgãos estaduais similares, uma Policia Federal rural, e o Exercito Brasileiro. Tudo conectado ainda com autoridades municipais, que tem muito a aprender com um Código novo que envolve todos os macro-biomas do país, e os mini-biomas que os pontilham, com especial atenção para as faixas litorâneas, faixas de contato entre as áreas nucleares de cada domínio morfoclimatico e fitogeográfico do território. Para pessoas inteligentes, capazes de prever impactos, a diferentes tempos do futuro, fica claro que ao invés da "estadualização", é absolutamente necessário focar para o zoneamento físico e ecológico de todos os domínios de natureza dos pais. A saber, as duas principais faixas de Florestas Tropicais Brasileiras: a zonal amazônica e a azonal das matas atlânticas o domínio dos cerrados, cerradoes e campestres: a complexa região semi-árida dos sertões nordestinos: os planaltos de araucárias e as pradarias mistas do Rio Grande do Sul, além de nosso litoral e o Pantanal Mato-grossense.

Seria preciso lembrar ao honrado relator Aldo Rabelo, que a meu ver é bastante neófito em matéria de questões ecológicas, espaciais e em futurologia - que atualmente na Amazônia Brasileira predomina um verdadeiro exercito paralelo de fazendeiros que em sua área de atuação tem mais força do que governadores e prefeitos. O que se viu em Marabá, com a passagem das tropas de fazendeiros, passando pela Avenida da Transamazônica, deveria ser conhecido pelos congressistas de Brasília, e diferentes membros do executivo. De cada uma das fazendas regionais passava um grupo de cinqüenta a sessenta camaradas, tendo a frente em cavalos nobres, o dono da fazenda e sua esposa, e os filhos em cavalos lindos. E, os grupos iam passando separados entre si, por alguns minutos. E, alguém a pé, como se fosse um comandante, controlava a passagem da cavalgada dos fazendeiros. Ninguém da boa e importante cidade de Marabá saiu para observar a coluna amedrontadora dos fazendeiros. Somente dois bicicletistas meninos, deixaram as bicicletas na beira da calçada olhando silentes a passagem das tropas. Nenhum jornal do Pará, ou alhures, noticiou a ocorrência amedrontadora. Alguns de nós não pudemos atravessar a ponte para participar de um evento cultural.

Será certamente, apoiados por fatos como esse, que alguns proprietários de terras amazônicas deram sua mensagem, nos termos de que "a propriedade é minha e eu faço com ela o que eu quiser, como quiser e quando quiser". Mas ninguém esclarece como conquistaram seus imensos espaços inicialmente florestados. Sendo que, alguns outros, vivendo em diferentes áreas do cetro-sul brasileiro, quando perguntados sobre como enriqueceram tanto, esclarecem que foi com os "seus negócios na Amazônia" (...). Ou seja, através de loteamentos ilegais, venda de glebas para incautos em locais de difícil acesso, os quais ao fim de um certo tempo, são libertados para madeireiros contumazes. E, o fato mais infeliz é que ninguém procura novos conhecimentos para re-utilizar terras degradadas. $\mathrm{Ou}$ exigir dos governantes tecnologias adequadas para revitalizar os solos que perderam nutrientes e argilas, tornando-se dominadas por areias finas (siltização).

Entre os muitos aspectos caóticos, derivados de alguns argumentos dos revisores do Código, destaca-se a frase que diz que se deve proteger a vegetação até sete metros e meio do rio. Uma redução de um fato que por si já estava muito errado, porém agora está reduzido genericamente a quase nada em relação aos grandes rios do país. Imagine-se que para o Rio Amazonas, a exigência protetora fosse apenas sete metros, enquanto para a grande maioria dos ribeirões e córregos também fosse aplicada a mesma exigência. Trata-se de desconhecimento entristecedor sobre a ordem de grandeza das redes hidrográficas do território intertropical brasileiro. $\mathrm{Na}$ linguagem amazônica tradicional, o próprio povo já reconheceu fatos referentes à tipologia dos rios regionais. Para eles, ali existem, em ordem crescente: igarapés, riozinhos, rios e parás. Uma última divisão lógica e pragmática, que é aceita por todos os que conhecem a realidade da rede fluvial amazônica.

Por desconhecer tais fatos os relatores da revisão aplicam o espaço de sete metros da beira de todos os cursos d'água fluviais sem mesmo ter ido lá para conhecer o fantástico mosaico de rios do território regional.

Mas o pior é que as novas exigências do Código Florestal proposto têm um caráter de liberação excessiva e abusiva. Fala-se em sete metros e meio das florestas beiradeiras (ripario-biomas), e, depois em preservação da vegetação de eventuais e distantes cimeiras. Não podendo imaginar quanto espaço fica liberado para qualquer tipo de ocupação do espaço. Lamentável em termos de planejamento regional, de espaços rurais e silvestres. Lamentável em termos de generalizações forçadas por grupos de interesse (ruralistas).

Já se poderia prever que um dia os interessados em terras amazônicas iriam pressionar de novo pela modificação do percentual a ser preservado em cada uma das propriedades de terras na Amazônia. $\mathrm{O}$ argumento simplista merece uma critica decisiva e radical. Para eles, se em regiões do centro-sul brasileiro a taxa de proteção interna da vegetação florestal é de $20 \%$, porque na Amazônia a lei exige 
$80 \%$. Mas ninguém tem a coragem de analisar o que aconteceu nos espaços ecológicos de São Paulo, Paraná, Santa Catarina, e Minas Gerais com o percentual de 20\%. Nos planaltos interiores de São Paulo a somatória dos desmatamentos atingiu cenários de generalizada derruição. Nessas importantes áreas, dominadas por florestas e redutos de cerrados e campestres, somente o tombamento integrado da Serra do Mar, envolvendo as matas atlânticas, os solos e as aguadas da notável escarpa, foi capaz de resguardar os ecossistemas orográficos da acidentada região. O restante, nos "mares de morros", colinas e várzeas do Médio Paraíba e do Planalto Paulistano, e próparte da Serra da Mantiqueira, sofreram uma derruição deplorável. É o que alguém no Brasil - falando de gente inteligente e bioética não quer que se repita na Amazônia Brasileira, em um espaço de $4.200 .000 \mathrm{~km}^{2}$.

Os relatores do Código Florestal, falam em que as áreas muito desmatadas e degradadas poderiam ficar sujeitas a "(re)florestamento" por espécies homogêneas pensando em eucalipto e pinus. Uma prova de sua grande ignorância, pois não sabem a menor diferença entre reflorestamento e florestramento. Esse último, pretendido por eles, é um fato exclusivamente de interesse econômico empresarial, que infelizmente não pretende preservar biodiversidades. Sendo que, eles procuram desconhecer que para áreas muito degradadas, foi feito um plano de (re)organização dos espaços remanescentes, sob o enfoque de revigorar a economia de pequenos e médios proprietários: Projeto FLORAM. Os eucaliptologos perdem éticos quando alugam espaços por 30 anos, de incautos proprietários, preferindo áreas dotadas ainda de solos tropicais férteis, do tipo dos oxissolos, e evitando as áreas degradadas de morros pelados reduzidas a trilhas de pisoteio, hipsométricas, semelhantes ao protótipo existente no Planalto do Alto Paraíba, em São Paulo. Ao arrendar terras de bisonhos proprietários, para uso em 30 anos, e sabendo que os donos da terra podem morrer quando se completar o prazo. Fato que cria um grande problema judicial para os herdeiros, sendo que ao fim de uma negociação as empresas cortam todas as árvores de eucaliptos ou pinos, deixando miríades de troncos no chão do espaço terrestre. Um cenário que impede a posterior reutilização das terras para atividades agrárias. Tudo isso deveria ser conhecido por aqueles que defendem ferozmente um Código Florestal liberalizante.

Por todas as razões somos obrigados a criticar a persistente e repetitiva argumentação do deputado Aldo Rebelo, que conhecemos há muito tempo, e de quem sempre esperávamos o melhor, no momento somos obrigados a lembrar a ele que cada um de nós tem que pensar na sua biografia, e, sendo político, tem que honrar a história de seus partidos. Mormente, em relação aos partidos que se dizem de esquerda e jamais poderiam fazer projetos totalmente dirigidos para os interesses pessoais de latifundiários.

Insistimos que em qualquer revisão do Código Florestal vigente, se deve enfocar as diretrizes através das grandes regiões naturais do Brasil, sobretudo domínios de natureza muito diferentes entre si, tais como a Amazônia, e suas extensíssimas florestas tropicais, e o Nordeste Seco, com seus diferentes tipos de caatingas. Tratam-se de duas regiões opósitas em relação à fisionomia e à ecologia, assim como em face das suas condições socioambientais. Ao tomar partido pelos grandes domínios administrados técnica e cientificamente por órgãos do executivo federal, teríamos que conectar instituições específicas do governo brasileiro com instituições estaduais similares. Existem regiões como a Amazônia que envolve conexões com nove estados do norte brasileiro. Em relação ao Brasil Tropical Atlântico os órgãos do Governo Federal - IBAMA, IPHAN, FUNAI e INCRA teriam que manter conexões com os diversos setores similares dos governos estaduais de norte a sul do Brasil. E assim por diante.

Enquanto o mundo inteiro repugna para a diminuição radical de emissão de $\mathrm{CO}_{2}$, o projeto de reforma proposto na Câmara Federal de revisão do Código Florestal defende um processo que significará uma onda de desmatamento e emissões incontroláveis de gás carbônico, fato observado por muitos críticos em diversos trabalhos e entrevistas.

Parece ser muito difícil para pessoas não iniciadas em cenários cartográficos perceber os efeitos de um desmatamento na Amazônia de até $80 \%$ das propriedades rurais silvestres. Em qualquer espaço do território amazônico, que vem sendo estabelecidas glebas nas quais se poderia realizar um desmate de até $80 \%$, haverá um mosaico caótico de áreas desmatadas e faixas inter-propriedades estreitas e mal preservadas. Lembrando ainda que, nas propostas de revisão, propriedades de alguns até 400 ha, teriam o direito de um desmate total em suas terras, vejo-me na obrigação de que a médio e longo prazo existiria um infernal caleidoscópio no espaço total de qualquer área da Amazônia. Nesse caso, as bordas dos restos de florestas, inter-glebas, ficarão à mercê de corte de árvores dotadas de madeiras nobres. E, além disso, a biodiversidade animal, certamente será a primeira a ser afetada de modo radical.

\section{A Cartografia da Reserva Legal}

Uma cartografia simbólica dos desmates, em propriedades de diferentes tamanhos, permite uma previsão visual do que seria a dinâmica do cenário do desmatamento regional, antevisto a médio prazo. Baseados em fatos reais já acontecidos no vale do Tocantins (Pará) e nos planaltos interiores de São Paulo e Minas Gerais.

No caso da Amazônia (o que mais nos preocupa), machadeiros e motoserristas - acompanhados de queimadas sincopadas - o roteiro dos desmatamentos seguiu por rodovias, ramais e sub-ramais, atingindo radicalmente as "espinhelas de peixe" dos loteamentos feitos em quarteirões especulativos no interior das matas biodiversas. Lotes de 50 a 100 ha, considerados pequenos na Amazônia, foram vendidos a incautos moradores de regiões distantes. Nesse último caso, os numerosos aquisidores, que nem mesmo puderam chegar ao sítio das terras compradas à distância, cederam o espaço para madeireiras espertas e persistentes. Fato que pode ser visto e analisado em imagens de satélite na região norte do Mato Grosso, no médio Tocantins, na Bragantina, Acre sul-oriental, Rondônia, Oeste-noroeste do Maranhão, e diversos outros setores das terras amazônicas.

Insistimos em prever que se houver um Código que limite a área de proteção das florestas a apenas $20 \%$ do espaço total de cada propriedade, seja qual for o seu tamanho, de 400 a 1.000 .000 de ha - o arrasamento a médio prazo será inimaginavelmente grande e progressivo.

Uma das justificativas mais freqüentes, para os que são favoráveis para a ampliação de áreas desmatáveis, - em cada propriedade de terra firme na Amazônia - é de que, assim, haverá mais emprego para trabalhadores amazonidas. Pouca gente lembra, entretanto, que em numerosas fazendas e fazendinhas da Amazônia Brasileira predomina o trabalho semi-escravo. Desde o início da ampliação das chamadas fronteiras ditas agrícolas, predominaram o trabalho braçal periódico ou temporário, para machadeiros, criadores de gado, madeireiros e plantadores de eucaliptos. Sendo que, nas raras áreas de solos melhores, estabeleceu-se o vai-e-vem tradicional de empregos no preparo da terra e plantio, em períodos limitados. E, mais tarde, diversas atividades na época da colheita. Caminhoneiros fizeram penetrações esdrúxulas para atingir locais de madeiras nobres ou transportar troncos de árvores para serrarias ou para o transporte de produtos das raras commodities. Agora, em espaços da soja, da cana, e muito eventualmente do arroz. Sendo que somente os capatazes mandonistas ganham razoavelmente.

Quem procura um emprego qualquer, em uma fazenda, ainda que temporário, sofre um drama trágico e muito cansativo. Para chegar 
à fazenda escolhida, marcham a pé com sua matulinha mirrada de roupas singelas, caminhando por quilômetros nas estreitas trilhas das florestas, até atingir as propriedades onde conseguirão um emprego braçal. Seja o preparo do solo para plantações; seja ampliação dos capinzais para o gado; seja no corte de árvores para ampliação dos espaços ditos produtivos; seja no trabalho rápido e esgotante nas épocas de colheitas. Quando despedidos são obrigados a voltar para áreas de beira de estradas onde existem rústicas aldeias ou "ruas" pseudo-comerciais.

Temos acompanhado, desde 1972, os problemas criados por capatazes autoritários em propriedades amazônicas, pertencentes a pessoas ou grupos de pessoas alienígenas. Conflitos dos mais diferentes tipos acontecem entre pobres trabalhadores silvos-rurais e os donos de propriedades dos mais diferentes tipos. Há uma resistência permanente em face à remuneração dos que vem de fora em face dos minguados preços pagos aos que nasceram na própria Amazônia. Reciprocamente, o comportamento dos proprietários em relação aos poucos tratos de terras férteis pertencentes a reservas indígenas, é catastrófico e quase insolúvel. Um dia encontrei em um aeroporto um proprietário de uma fazenda, que ia viajar para a Amazônia no Noroeste da Roraima, onde possuía suas terras. Perguntei-lhe, qual era a relação entre seus camaradas e os índios yanomamis da região, e a resposta infeliz veio rápida e antiética: "Para eles, é o meu capataz que responde, erguendo seu perigoso facão".

Numa ocasião, ao término de uma visita a uma fazenda dedicada à pecuária, nos pediram que em nossa volta levássemos para uma farmácia um camarada doente, que estava passando muito mal. $\mathrm{Na}$ realidade, era alguém que contraiu uma malária radical, designada por "tersã maligna". Não dá para falar sobre o triste estado do pobre trabalhador, sentado no banco detrás do meu carro. Na farmácia, tomamos conhecimento que em casos similares a única providencia era um coquetel de remédios agressivos, através dos quais, o pobre doente "melhorava ou morria".

$\mathrm{Na}$ rodovia entre Rio Branco e Brasiléia (Acre), pudemos sentir o ódio que alguns jovens tinham para o que chamavam de "paulistas", os quais teriam comprado terras durante os trabalhos de construção da estrada. O desmate interfluvial fez com que as cabeceiras de igarapés secassem; e que muitas propriedades da terra firme desmatada, ficassem sem qualquer atividade produtiva. Explicação dos acreanos: inadimplência dos proprietários alienígenas "porque nunca eles quiseram fazer uma parceria conosco, que temos muito mais experiência sobre atividades agrárias em nossa região". Note-se que o termo "paulista" dizia respeito a qualquer pessoa procedente do centro sul do Brasil. Tal como nessa imensa área, todos os migrantes são designados por "baianos", independentemente de onde tenham vindo.

\section{Os Pequenos Produtores}

Aqui chegados em nossas considerações, torna-se indispensável referir-se a atividades de pequenos produtores familiares, dotados de terras mais férteis, de dimensões limitadas, tais como várzeas de ricos solos fluvio-aluviais ao longo do Rio Amazonas, ou de pequenas áreas de terra firme dotadas de oxisolos oriundos da decomposição de basaltos ou diabásios (infelizmente porém, essas últimas áreas são bastante raras, envolvendo em seu espaço total menos de oito mil quilômetros quadrados). Ou em um modelo localizado de plantações em praias de estiagem do Rio Acre. Ou, onde vicejam linearmente melancias, melões e algumas plantas alimentares. Ou em bordas de florestas restantes em terrenos de projetos falidos, onde se estabeleceu o importante e famoso projeto RECA. Houve um tempo em que muito se falou em reservas extrativistas, a partir do Acre de Chico Mendes, ampliado para todo o território amazônico. Evidentemente, houve muito exagero nessa campanha, tão simpática quanto inviável. Mas aconteceu felizmente, uma proposta bem mais complexa e diversificada, que pode ter grande aplicação a curto e médio prazo; a qual introduzia atividades mais lógicas e produtivas, sem de tudo eliminar o sentido complementar do extrativismo. Trata-se de um modelo pioneiro, inventado por um expadre francês, de origem rural, que após conhecer o Paraná foi para o Acre com a idéia de trabalhar na reutilização de áreas degradadas. Após conversar com o inteligente Bispo Don Grec, em Rio Branco resolveu fazer uma experiência extremamente válida e quase científica porque se utilizou do chamado "efeito de borda" para iniciar plantações com espécies amazônicas, tais como açaí, cupuaçu e pupunha. Seu projeto foi feito em cooperação com amazonidas residentes na fronteira da Rondônia com o Acre, tendo foco inicial na pequena cidade de Nova Califórnia.

Nenhum governo soube perceber o quanto o projeto ali instalado e desenvolvido, poderia ser útil para numerosas outras áreas de borda de matas remanescentes. Sem falar que no seio da floresta continuava o projeto extrativista tão caro aos companheiros do extraordinário acreano Chico Mendes. Além do que, o chamado "reflorestamento econômico concentrado e adensado" (RECA), teve um caráter didático para os cooperados que se integraram no trabalho, produzindo espécies amazônicas e produtos comestíveis importantes para sua alimentação (como açaí, abacaxis, castanhas e, sobretudo mandioca). Na borda das florestas, devido à forte luminosidade e hidratação caída das folhas e galhos poderão ser produzidas muito mais coisas ainda, a favor dos amazonidas, tais como bananeiras e mamoeiros, e diversas outras plantas frutíferas. Muita coisa ainda resta ser analisada, no famoso projeto, que infelizmente foi muito pouco compreendido por técnicos e governantes.

Nas mudanças que se pretendem fazer para o atual Código Florestal existem alguns tópicos extremamente criticáveis. Ao se discutir o tamanho de propriedades familiares definiu-se as mesmas até 400 ha. Fato que significa que todas as pequenas e médias propriedades produtoras, ou parcialmente aproveitadas, até 400 ha poderão ser totalmente desmatadas. $\mathrm{O}$ fato de considerar o espaço de propriedades familiares até o nível de 400 ha é um absurdo total. Trata-se de uma excessiva flexibilização que poderá produzir um mosaico derruidor de florestas ao longo de rodovias, estradas, riozinhos e igarapés. Um cenário trágico para o futuro, em processo no interior da Amazônia brasileira. No entanto, propriedade de $100 \mathrm{a}$ 400 ha, que conservassem um razoável percentual de matas no seu entorno, poderiam receber esquemas parecidos com o projeto RECA, na borda dos remanescentes florestais. Fato que não foi considerado nem de passagem pelos idealizadores e relatores de um novo Código Florestal. Razão pela qual deixamos aqui além de uma crítica que julgamos absolutamente necessária, uma proposição de acréscimos de atividades para pequenas e médias propriedade familiares. Lembrando que quem faz críticas tem que elaborar propostas bem planejadas para resolver as situações consideradas negativas.

Anotamos ainda que a idéia de reduzir para $15 \mathrm{~m}$ faixas de proteção de florestas beiradeiras (mini-biomas ripários) tem um caráter extremamente genérico e de duvidosa aplicabilidade. A nosso ver não é possível limitar generalizadamente as áreas beiradeiras, em termos de alguns metros de largura. Pelo contrário, é necessário considerar os fatos relacionados a igarapés, riozinhos, rios, e "parás" (grandes rios), utilizando a tipologia popular amazonida. A impressão que se tem é de que, determinando uma largura geral para proteção, estaríamos possibilitando desmates no nível de todos os espaços situados entre a beira de cursos d'água até muito além onde se situam os interflúvios de colinas ou encostas de pequenas serranias amazônicas. Existe toda uma aula a ser dada sobre essa problemática que tende a criar cenários extremamente caóticos em relação ao futuro a diferentes profundidades de tempo. 


\section{Considerações Finais}

Um comentário quase final: não se faz qualquer projeto de interesse nacional pensando apenas em favorecer de imediato só uma geração do presente, em termos de especulação com espaços ecológicos, mesmo porque, somos de opinião que devemos pensar no sucesso de todos os grupos humanos, ao longo de muito tempo. Uma questão de bioética com o futuro. Sem pensar na grande capacidade que o conjunto das imensas florestas equatoriais zonais preservadas da Amazônia, tem em relação ao clima do planeta Terra; assunto que preocupa todos os pesquisadores sensíveis do mundo. Gente que espera que o Brasil faça uma proteção integrada da maior área de vegetação florestal que ainda resta em regiões equatoriais e sub-equatorias do mundo. Será muito triste, cultural e politicamente falando, que pessoas de diversas partes do mundo ao lerem as mudanças absurdas pretendidas para o Código Florestal, venham a dizer que fica comprovado que "o Brasil não tem capacidade para administrar e gerenciar a Amazônia”. Ainda que em outros países haja um interesse permanente em adquirir por preços irrisórios as madeiras do território amazônico. Tristes frases que sempre vem sendo ditas ao sabor de trágicos acontecimentos ocorridos em nossa principal área de vegetação florestal, que se estende por alguns milhões de quilômetros quadrados.
A utopia de um desenvolvimento com o máximo de florestas em pé não pode ser eliminada por princípio em função de mudanças radicais do Código Florestal, sendo necessário pensar no território total de nosso país, sob um ampliado e correto Código de Biodiversidade. Ou seja, um pensamento que envolva: as nossas grandes florestas (Amazônia e Matas Tropicais Atlânticas); o domínio das caatingas e agrestes sertanejos; planaltos centrais com cerrados, cerradões e campestres; os planaltos de araucárias sul-brasileiros; as pradarias mistas do Rio Grande do Sul; e os redutos e mini-biomas da costa brasileira e do Pantanal mato-grossense, e faixas de transição e contrato (core-áreas) de todos os domínios morfoclimáticos e fitogeográficos brasileiros).

Seria necessário que os pretensos reformuladores do Código Florestal lançassem sobre o papel os limites de glebas de quinhentos a milhares de hectares, e dentro de cada parcela das glebas colocasse indicações de $20 \%$ correspondente às florestas ditas preservadas. E, observando o resultado desse mapeamento simulado, poderiam perceber que o caminho da devastação lenta e progressiva iria criar alguns quadros de devastação similares ao que já aconteceu nos confins das longas estradas e seus ramais, em espaços de quarteirões implantados para venda de lotes de 50 a 100 ha, onde o arrasamento de florestas no interior de cada quarteirão foi total e inconseqüente, decorridos poucos anos. 
